\title{
CASPASE 3 AS PROGNOSTIC MARKER FOR TRIPLE NEGATIVE BREAST CANCER CHEMOTHERAPY
}

\section{KAMAL BASRI SIREGAR ${ }^{1,2,3 *}$, TJAKRA WIBAWA MANUABA ${ }^{4}$, MUHAMMAD NADJIB DAHLAN LUBIS ${ }^{5}$, ROSITA JUWITA SEMBIRING ${ }^{6}$}

${ }^{1}$ Department of Surgery, Division of Surgical Oncology, Haji Adam Malik General Hospital Medan, Universitas Sumatera Utara, Indonesia. ${ }^{2}$ Stem Cells Program, Universitas Sumatera Utara, Indonesia. ${ }^{3}$ Nanomedicine Program, Universitas Sumatera Utara, Indonesia. ${ }^{4}$ Departement of Surgery, Division of Surgical Oncology, Sanglah Hospital, Udayana University, Bali, Indonesia. ${ }^{5}$ Department of Anatomical Pathology, University of Sumatera Utara, Indonesia. ${ }^{6}$ Department of Clinical Pathology, University of Sumatera Utara, Indonesia. Email: siregarkamalbasri@gmail.com

Received: 05 June 2017, Revised and Accepted: 02 August 2017

ABSTRACT

Objectives: This study will examine the expression of caspase-3 and apoptotic index (AI) in triple negative breast cancer (TNBC). By knowing the non-responsiveness effect earlier, adverse effects of chemotherapy can be avoided.

Methods: This prospective cohort study has been approved by the local Ethics Committee. A total of 60 consent TNBC patients from Haji Adam Malik General Hospital and Bunda Thamrin Hospital were included in the study. Patients with heart, kidney, liver disease, history of surgery, chemotherapy, or hormonal therapy were excluded. Samples were analyzed immunohistochemically by monoclonal antibodies to assess caspase 3 and AI. Clinical chemotherapy response is determined as a positive or negative response based on Response Evaluation Criteria in Solid Tumors.

Results: The results of this study indicated that caspase 3 was increased post-chemotherapy but could not predict the clinical response of chemotherapy. Caspase- 3 post-chemotherapy $(5.27 \pm 1.27 \mathrm{pg} / \mathrm{mL})$ compared to pre-chemotherapy $(4.60 \pm 1.09 \mathrm{pg} / \mathrm{mL})$ increased significantly $(\mathrm{p}=0.003$ ) by $0.67 \pm 1.66 \mathrm{pg} / \mathrm{mL}$ but no difference was found in AI score $(\mathrm{p}=0.819)$. Neither caspase 3 nor the AI were associated with a clinical chemotherapy response $(\mathrm{p}=0.514$ and $\mathrm{p}=0.993$, subsequently).

Conclusion: Further research with larger samples is needed to determine the role and pathway of chemotherapy induced caspase 3 rise.

Keywords: Triple negative breast cancer, Chemotherapy, Caspase, Apoptosis.

(C) 2017 The Authors. Published by Innovare Academic Sciences Pvt Ltd. This is an open access article under the CC BY license (http://creativecommons. org/licenses/by/4. 0/) DOI: http://dx.doi.org/10.22159/ajpcr.2017.v10i11.20451

\section{INTRODUCTION}

Triple negative breast cancer (TNBC) accounts for $17-21 \%$ of breast cancer cases [1] but accounts for the worst prognosis of all breast cancers due to its complexity [2]. The absence of hormonal receptors makes chemotherapy an important role in the treatment of TNBC [3]. Multicenter studies showed that $36 \%$ of TNBC patients receiving neoadjuvant chemotherapy showed complete clinical response and a significant good prognosis for disease-free survival ( $p=0.001$ ) [4]. In the EORTC study, it was reported that almost 23\% of patients being enabled for breast-conserving surgery after neoadjuvant chemotherapy. However, there were also many chemoresistance cases making the neoadjuvant chemotherapy almost had no benefit but only yielded harmful side effects [5]. Biomarker for that can accurately identify a patient with sensitivity for chemotherapy is needed [6].

Although biomolecular of breast cancer is one of the most heterogeneous cancers of genomic variation [7], the activation of apostrophic signaling in chemotherapy is demonstrated by activation of mitochondrial pathway apoptosis and signals through the death receptor (extrinsic pathway) that contribute to the sensitivity of tumor cells to cytotoxic therapy [8]. Both pathways will eventually activate the caspase and effector molecules resulting in cell death. Apoptosis assessment appears as an idea to determine the prognosis and predictive factors of the chemotherapy response [9]. This is reinforced as numerous studies have shown that conventional predictor factors such as tumor size and lymphatic status cannot be applied to patients as a whole [10].

This study will examine the expression of caspase- 3 and apoptotic index (AI). Caspase-3 encoded by the CASP3 gene [11] is one of the apoptotic executants that activate endonucleases causing DNA fragmentation in apoptotic mechanisms. On the other hand, in histopathology, the AI is used as a measure of apoptotic or apoptotic cell count per 1000 tumor cells [12]. No research in Indonesia has been done about this topic before.

The aim of this study is to determine the relationship of either caspase- 3 score or apoptosis index with clinical chemotherapy response of neoadjuvant chemotherapy in TNBC patients.

\section{METHODS}

Data selection

This prospective cohort was conducted from June 2015 to February 2017. As many as 60 TNBC subjects undergoing surgery in Haji Adam Malik General Hospital and Bunda Thamrin Hospital were included in this study. They must approve the informed consent and had a Karnofsky scale $>70$. Exclusion criteria when there is morbidity of heart disease, kidney, liver, history of surgery, hormonal therapy, or previous chemotherapy.

\section{Study parameters}

The parameters of this study were caspase 3 pre-chemotherapy and post-chemotherapy, pre-chemotherapy and post-chemotherapy apoptotic indices, and clinical responses. Samples were analyzed immunohistochemically to assess caspase 3 and the $\mathrm{AI}$ in the laboratory. Clinical chemotherapy response was classified based on Response Evaluation Criteria in Solid Tumors (RECST) with or without response. 
Analysis of caspase 3

Caspase 3 was checked with a monoclonal antibody kit. Breast tumor tissue was fixed with a $10 \%$ formalin buffer for 30 minutes and processed in paraffin block form for $48 \mathrm{hrs}$. The specimens were stored in room temperature, and glass object must be remained in wet conditions to ensure well painted. The specimen then reacted with peroxidase block for 1-5 minutes, cleaning over buffer, application of antibody or negative control reagents, addition of peroxidase labeled polymer for 30 minutes, chromogen substrate for 5-10 minutes, counterstained with hematoxylin, and until the specimen was ready for mounting.

\section{Analysis of AI}

An AI examination was performed with a TUNEL assay. Endogenous peroxidase activity was deactivated with $1 \%$ hydrogen peroxide in phosphate-buffered saline (PBS) at $\mathrm{pH} 7.4$ for 10 minutes. The nucleus was cut and cleansed or stripped of the protein by incubation process with $0.5 \%$ pepsin at $\mathrm{pH} 2.0$ for 30 minutes at $37^{\circ} \mathrm{C}$ and then washed with distilled water to remove the pepsin. Each of these pieces (nucleus) is ready to be processed through a TUNEL procedure that was incubated in Tris buffer ( $\mathrm{pH}$ 7.6) for 5 minutes and then for $1 \mathrm{hr}$ temperature of $37^{\circ} \mathrm{C}$ in $100 \mu \mathrm{L}$. The mixture consists of 15 units of pure FPLC (Pharmacia, Windsor, Berkshire, UK), 0.5 nmol biotin-16-dUTP (Boehringer Mannheim, Mannheim, Germany), $5 \mathrm{mM}$ cobalt chloride, $0.2 \mathrm{M}$ sodium cacodylate, $25 \mathrm{mM}$ Tris $\mathrm{HCl}$ (PH 6.6), and $0.25 \mathrm{mg} / \mathrm{ml}$ of bovine serum albumin were dissolved in distilled water. After rinsing or cleaning intensively then incubated 30 minutes at room temperature in a solution of 1: 400 ratio of horseradish peroxidase conjugated to streptavidin (Dako UK Ltd.) in PBS supplemented (1\% PBS and 0.5\% Tween 20). The color occurred 10 minutes, using a $0.05 \%$ mixture of diaminobezidine, $0.07 \%$ imidazole, $0.1 \%$ hydrogen peroxide, and $0.5 \%$ copper sulfate with $0.9 \%$ sodium chloride for 1 minute. Finally, the core pieces of the cell have been processed, performed counterstained in Mayer's hematoxylin, dehydrated, cleared in xylene and mounted in DPX. The AI was assessed by counting cancer cells at 400 times magnification (Burcombe et al., 2008).

\section{Clinical chemotherapy response interpretation}

The clinical chemotherapy response assessment process is evaluated according to the RECST (Cizmarikova et al., 2010) by comparing tumor size before and after neoadjuvant chemotherapy. Breast tumors are determined locally and drawn on the surface of the breast skin, then ascertained the longest and the shortest size of the tumor. Diameter is measured from the longest measure, the volume is determined from the longest size multiplied by the shortest size. The size of the tumor after the third series neoadjuvant chemotherapy will be used as the final measure that determines the tumor's response rate. The tumor response rate was measured by comparing the initial size of the tumor.

\section{RESULTS}

A total of 60 TNBC patients followed the study until completion. Subjects ranged from 30 to 73 years old with the majority of premenopausal subjects $(56.7 \%)$. As many as $75 \%$ of patients diagnosed in Stage IIIB and $43.3 \%$ had T3 tumor size, $80 \%$ IDC histology type, and $41.7 \%$ were in Grade II. After 3 cycles of neoadjuvant chemotherapy, 31 subjects (51.7\%) did not show clinical response while 29 subjects (48.3\%) had a clinical response (Table 1).

Various biomarkers have been used in assessing apoptosis directly or indirectly. This study was conducted to determine the relationship of caspase- 3 and AI with astrocytoma grade and clinical outcome. The value of caspase 3 pre-chemotherapy was $4.60 \pm 1.09 \mathrm{pg} / \mathrm{mL}$ and postchemotherapy was $5.27 \pm 1.27 \mathrm{pg} / \mathrm{mL}$. Analysis with t-paired test showed that there was a significant difference in mean score of caspase 3 postchemotherapy compared to pre-chemotherapy as indicated by $\mathrm{p}=0.003$. There was an increase of 1.15 times or by $0.67 \pm 1.66 \mathrm{pg} / \mathrm{mL}$ of caspase 3 post-chemotherapy (Table 2 ). On the other hand, the mean AI before chemotherapy was $5.47 \pm 1.38 \mathrm{pg} / \mathrm{mL}$ and after chemotherapy was
Table 1: Demographics data of subjects

\begin{tabular}{ll}
\hline Characteristics & Percentage \\
\hline Age (years old) & \\
$<35$ & $8(13.3)$ \\
$35-40$ & $11(18.3)$ \\
$41-50$ & $16(26.7)$ \\
$51-60$ & $19(31.7)$ \\
$>60$ & $6(10.0)$ \\
Menopausal status & \\
Premenopause & $34(56.7)$ \\
Postmenopause & $26(43.3)$ \\
Stage & \\
IIIA & $15(25.0)$ \\
IIIB & $45(75.0)$ \\
Tumor size & $3(5.0)$ \\
Tx & $1(1.7)$ \\
T1 & $26(43.3)$ \\
T3 & $30(5.0)$ \\
T4 & \\
Histological type & $48(80.0)$ \\
IDC & $12(20.0)$ \\
ILC & \\
Grade & $9(15)$ \\
I & $26(43.33)$ \\
II & $25(41.66)$ \\
III & \\
Remotherapy response & $29(48.3)$ \\
No response & $31(58.7)$ \\
\hline &
\end{tabular}

$5.52 \pm 1.08 \mathrm{pg} / \mathrm{mL}$. The result of $\mathrm{t}$-paired test showed that there was no significant difference between the mean of AI post-chemotherapy and pre-chemotherapy ( $\mathrm{p}=0.819$ ) with only increase of $0.05 \pm 1.68 \mathrm{pg} / \mathrm{mL}$ (Table 3).

Most of the subjects in the group that responded nor responded clinically to chemotherapy showed an increased caspase 3 score $(61.7 \%)$ and an increased AI (51.7\%). However, Phi and Cramer's V correlation analysis showed no significant difference of caspase $3(p=0.514$, Table 4$)$ and apoptosis index ( $\mathrm{p}=0.993$, Table 5) with clinical response to neoadjuvant chemotherapy on TNBC. However, in the unresponsive group (14 out of 31 samples, $45.2 \%$ ) showed a significantly lower caspase 3 score than the response group ( 9 of 29 samples, 31\%).

\section{DISCUSSION}

The age-specific prevalence pattern for TNBC was not fully understood until SEER collected data from 1997 to 2002 [13]. In this study, subjects aged 27-73 years old that mostly aged between 51 and 60 years (31.7\%). Prevalence of subjects aged $35-50$ years old was $76.7 \%$. This result was in accordance with SEER survey that found peak incidence cases of TNBC from 35 to 60 years, and afterward not much different. The population based study by Ambrosone et al. showed that 2.9 times the increased risk of TNBC in women at this age was due to an unknown increase in the use of oral contraceptives [14]. However, there is a research controversy by Stark et al. who observed increased 1.9 times risk of TNBC occurred at younger ages. However, this can be due to the researchers comparing it with luminal breast cancer [15]. Phipps et al. in Americans showing that menopausal age was not associated with an increased risk of TNBC, as did other studies in China [16] and Poland [17] but increased the risk of luminal breast cancer A. Phipps et al. even tried hormonal therapy on TNBC patients and found no improvement. The study also showed a nearly equal proportion between premenopausal and postmenopausal patients, $56.66 \%$ and $43.33 \%$, respectively [18].

Based on Table 1, there were 31 samples (51.7\%) that did not respond to neoadjuvant chemotherapy and 29 samples $(48.3 \%)$ that response to neoadjuvant chemotherapy. This proportion was higher than that of Yarso et al., which showed only 15\% of clinical responses [19] although 
Table 2. Mean difference of caspase 3 postchemotherapy and prechemotherapy

\begin{tabular}{lllll}
\hline Parameter & Before chemotherapy $(\mathbf{p g} / \mathbf{m L})$ & After Kemoterapi $(\mathbf{p g} / \mathbf{m L})$ & Difference & p \\
\hline Caspase-3 & $4.60+1.09$ & $5.27+1.27$ & Increase $0.67+1.66$ & 0.003 \\
\hline
\end{tabular}

Table 3. Mean difference of apoptotic index postchemotherapy and prechemotherapy

\begin{tabular}{lllll}
\hline Parameter & Before chemotherapy $(\mathbf{p g} / \mathbf{m L})$ & After Kemoterapi $(\mathbf{p g} / \mathbf{m L})$ & Difference & $\mathbf{p}$ \\
\hline Apoptotic index & $5.47+1.38$ & $5.52+1.08$ & Increase $0.05+1.68$ & 0.003 \\
\hline
\end{tabular}

Table 4. The relationship between caspase 3 and neoadjuvant chemotherapy response

\begin{tabular}{|c|c|c|c|c|}
\hline \multirow[t]{2}{*}{ Caspase 3} & \multicolumn{2}{|l|}{ Clinical response } & \multirow{2}{*}{\multicolumn{2}{|c|}{ Total (\%) p }} \\
\hline & Unresponsive (\%) & Responsive (\%) & & \\
\hline Unchanged & 7 (11.7) & $4(6.7)$ & $11(18.3)$ & 0.514 \\
\hline Decrease & 7 (11.7) & $5(8.3)$ & $12(20.0)$ & \\
\hline Increase & $17(28.3)$ & $20(33.3)$ & 37 (61.7) & \\
\hline Total & 31 (51.7) & $29(48.3)$ & $60(100)$ & \\
\hline
\end{tabular}

Table 5. The relationship between apoptotic index and neoadjuvant chemotherapy response

\begin{tabular}{lllll}
\hline \multirow{2}{*}{$\begin{array}{l}\text { Apoptotic } \\
\text { index }\end{array}$} & \multicolumn{2}{l}{ Clinical response } & Total (\%) & $\mathbf{p}$ \\
\cline { 2 - 4 } & $\begin{array}{l}\text { Unresponsive } \\
\text { (\%) }\end{array}$ & $\begin{array}{l}\text { Unresponsive } \\
\mathbf{( \% )}\end{array}$ & & \\
\hline Unchanged & $4(12.9)$ & $4(6.7)$ & $8(13.3)$ & 0.993 \\
Decrease & $11(18.3)$ & $10(16.7)$ & $21(35.0)$ & \\
Increase & $16(26.7)$ & $15(25.0)$ & $31(51.7)$ & \\
Total & $31(51.7)$ & $29(48.3)$ & $60(100)$ & \\
\hline
\end{tabular}

Torrisi et al. reported 77.5\% [20]. von Minckwitz et al. found that the addition of neoadjuvant chemotherapy carboplatin to the regimen taxane, anthracycline, and targeted therapies significantly increase the proportion of patients achieving a complete response. This suggested that neoadjuvant chemotherapy could reduce the size of the tumor and eradicated almost half the TNBC cases [21]. Otherwise, some unresponsive patients to be overtreated because of the unpredictability of TNBC. This condition should be prevented by the discovery of prognostic factor that can predict neoadjuvant chemotherapy response earlier.

Caspase- 3 as the executor or effector on the apoptotic process plays an important role in assessing the response of a cell to chemotherapy or cytotoxic substances. The killing of cancer cells by chemotherapeutic agents is based on apoptotic mechanisms, both intrinsic and extrinsic, with caspase 3 as the apoptotic executor [22]. Looking at the abovementioned caspase- 3 potential, Devarajan et al. studied the regulation of caspase-3 using cell culture of breast cancer (MCF-7) administered doxorubicin. The results showed that there was an increase in caspase- 3 and its receptor downregulation which confirmed the idea of caspase 3 as a promising marker of the effectiveness of chemotherapeutic agents [23]. However, Salakou's et al. showed that caspase 3 alone was less useful. The researchers proposed that the use of Bax/Bcl-2 ratio predicted better than caspase-3 alone [24]. In this study, there was a significant difference ( $\mathrm{p}=0.003$ ) with an increase of 1.15 times $(0.67 \pm 1.66 \mathrm{pg} / \mathrm{mL})$ of caspase-3 post-chemotherapy compared to prechemotherapy. This result suggested that neoadjuvant chemotherapy managed to trigger this apoptotic apoptosis mediator in the TNBC network. Although the assessment of the relationship between clinical response and caspase 3 after and before neoadjuvant chemotherapy was not statistically significant $(\mathrm{p}=0.514$; Table 4$)$, the clinical data analysis showed that only a few chemosensitive subjects had decreased or unchanged caspase 3 score $(31 \%)$ compared to subjects with no chemotherapy response (45.2\%). Caspase 3 in the group with positive chemotherapy response tended to increase $(69 \%)$ compared to the group without clinical response (54.8\%).

Reviewing the AI, there was no significant mean difference between post-operative and post-chemotherapy $(\mathrm{p}=0.819)$, and no significant differences were found between $\mathrm{AI}$ and TNBC chemotherapy response $(p=0.993)$. The proportion of the increase or decrease in the AI was almost comparable between those who responded and unrespond to neoadjuvant TNBC. This result was similar to Yang et al. which showed that maybe the AI low due to the low concentration of doxorubicin given. In MCF-7 cells, $18 \mathrm{hrs}$ doxorubicin were exposed that resulted in caspase activation and other apoptotic substrates in line with the addition of 2-10 microM [25]. Unlike O'Donovan et al. study in 103 breast tissue samples, they showed that caspase-3 precursor and active form were higher in breast cancer than normal tissue $(\mathrm{p}=0.0188$; $\mathrm{p}=0.0002$ ) [26]. Similarly, Sharma et al. showed that tumor biology markers (Bcl-2, AI and Caspase-3) change occurred 24-48 hrs after first neoadjuvant chemotherapy cycles. These markers could be as a factors to predict the response of chemotherapy but to prove them statistically need research with a larger sample size [27].

It has been shown in the previous data that there was a significant increase in caspase 3 after neoadjuvant chemotherapy but no significant increase in apoptosis index. The author concluded that there were other apoptotic pathways other than the normal extrinsic and intrinsic pathways that triggered caspase 3 so that the AI was normal but caspase 3 increased. On the other hand, the associated caspase 3 score may be a type 1 error in the study. The caspase 3 score that was found to be unrelated to clinical response should still be further investigated in larger samples because although statistically unrelated, samples with caspase 3 increased were found more in the group with than those without chemotherapy response.

\section{CONCLUSION}

There were no significant differences of either caspase 3 score or AI with clinical chemotherapy response to neoadjuvant chemotherapy on TNBC. Further research with larger samples is needed to determine the role and pathway of chemotherapy induced caspase 3 rise.

\section{REFERENCES}

1. Wu J, Li S, Jia W, Su F. Response and prognosis of taxanes and anthracyclines neoadjuvant chemotherapy in patients with triplenegative breast cancer. J Cancer Res Clin Oncol 2011;137(10):1505-10.

2. Ponvinobala K, Kanchana G, Rubalakshmi G. In vitro anticancer activity of hydro-alcohol extract of leaves of Andrographis neesiana aginst PC-3 and MCF-7 cell lines. Int J Pharm Pharm 2012;4(3):396-9.

3. Liedtke C, Mazouni C, Hess KR, Andre F, Tordai A. Response to neoadjuvant therapy and long-term survival in patients with triplenegative breast cancer. J Clin Oncol 2011;6(8):1275-81.

4. Fisher B, Brown A, Mamounas E, Wieand S, Robidoux A, Margolese $\mathrm{RG}$, et al. Effect of preoperative chemotherapy on local-regional disease in wome with operable breast cancer: Findings from National Surgical Adjuvant Breast and Bowel Project B-18. J Clin Oncol 1997;15(7):2483-93.

5. Indran IR, Tufo G, Pervaiz S, Brenner C. Recent advances in apoptosis, mitochondria and drug resistance in cancer cells. Biochim Biophys 
Acta 2011;1807(6):735-45.

6. Rakha EA, Reis-Filho JS, Baehner F, Dabbs DJ, Decker T, Eusebi V, et al. Breast cancer prognostic classification in the molecular era: The role of histological grade. Breast Cancer Res 2010;12(4):207.

7. Omar MS, Crowe A, Hughes J. Distribution of the single nucleotide polymorphism C3435T of MDR1 gene among people in Western Australia. Int J Pharm Pharm 2013;5(4):470-3.

8. Bao Q, Shi Y. Apoptosome: A platform for the activation of initiator caspases. Cell Death Differ 2007;14(1):56-65.

9. Rastogi R, Richa P, Sinha RP. Apoptosis: Molecular mechanisms and pathogenicity. EXCLI J 2009;8:155-81.

10. van der Hage JA, Mieog JS, van de Velde CJ, Putter H, Bartelink H, van de Vijver MJ. Impact of established prognostic factors and molecular subtype in very young breast cancer patients: Pooled analysis of four EORTC randomized controlled trials. Breast Cancer Res 2011;13(3):R68.

11. Alenzi FQ, Lotfy M, Wyse R. Swords of cell death: Caspase activation and regulation. Asian Pac J Cancer Prev 2010;11(2):271-80.

12. Luo M, Lu Z, Sun H, Yuan K, Zhang Q, Meng S, et al. Nuclear entry of active caspase-3 is facilitated by its p3-recognition-based specific cleavage activity. Cell Res 2010;20(2):211-22.

13. Surveillance Epidemiology and End Results (SEER) Program. SEER/ stat database: Incidence-SEER 13 regs research data, Nov 2009 Sub (1992-2007) - Linked to county attributes - Total US 1969-2007 counties, National Cancer Institute. Cancer Stat 2010;1:1-89.

14. Ambrosone CB, Zirpoli G, Ruszczyk M, Shankar J, Hong CC, Mcllwain D, et al. Parity and breastfeeding among African-American women: Differential effects on breast cancer risk by estrogen receptor status in the Women's Circle of Health Study. Cancer Causes Control 2014;25(2):259-65.

15. Stark A, Kapke A, Schultz D, Brown R, Linden M, Raju U. Advanced stages and poorly differentiated grade are associated with an increased risk of HER2/neu positive breast carcinoma only in White women: Findings from a prospective cohort study of African-American and White-American women. Breast Cancer Res Treat 2008;107(3):405-14.

16. Xing $\mathrm{P}, \mathrm{Li} \mathrm{J}$, Jin $\mathrm{F}$. A case-control study of reproductive factors associated with subtypes of breast cancer in Northeast China. Med Oncol 2010;27:926-31.

17. Yang, HL, Chen CS, Chang WH, Lu FJ, Lai YC, Chen CC, et al. Growth inhibition and induction of apoptosis in MCF-7 breast cancer cells by antrodia camphorata. Cancer Lett 2006;231(2):215-27.
18. Phipps AI, Buist DS, Malone KE, Barlow WE, Porter PL, Kerlikowske K, et al. Reproductive history and risk of three breast cancer subtypes defined by three biomarkers. Cancer Causes Control 2011;22(3):399-405

19. Yarso KY, Sudarsa IW, Manuaba IB. Clinical initial response of neoadjuvant chemotheraphy in triple negative, HER-2, and luminal types of breast cancer in denpasar (a preliminary study). Bali Med J 2012;1(1):12-6.

20. Torrisi R, Balduzzi A, Ghisini R, Rocca A, Bottiglieri L, Giovanardi F, et al. Tailored preoperative treatment of locally advanced triple negative (hormone receptor negative and HER2 negative) breast cancer with epirubicin, cisplatin, and infusional fluorouracil followed by weekly paclitaxel. Cancer Chemother Pharmacol 2008;62(4):667-72.

21. von Minckwitz G, Eidtmann H, Loibl S, Blohmer JU, Costa SD, Fasching PA, et al. Integrating bevacizumab, everolimus, and lapatinib into current neoadjuvant chemotherapy regimen for primary breast cancer. Safety results of the GeparQuinto trial. Ann Oncol 2011;22(2):301-6.

22. Salako O, Poku R, Nkembo A, Amissah F, Ntantie E, Lamango N. Treatment of triple negative breast cancer-derived cells with polyisoprenylated cysteinyl amide inhibitors activates caspase $3 / 7$ and disrupts F-actin organization leading to apoptosis and diminished cell motility. Faseb 2016;30(1):1-3.

23. Devarajan E, Sahin AA, Chen JS, Krishnamurthy RR, Aggarwal N, Brun AM, et al. Down-regulation of caspase 3 in breast cancer:A possible mechanism for chemoresistance. Oncogene 2002;21(57):8843-51.

24. Salakou S, Kardamakis D, Tsamandas AC, Zolota V, Apostolakis E, Tzelepi V, et al. Increased Bax/Bcl-2 ratio up-regulates caspase-3 and increases apoptosis in the thymus of patients with myasthenia gravis. In Vivo 2007;21(1):123-32.

25. Yang XH, Sladek TL, Liu X. Reconstitution of caspase-3 sensitizes MCF-7 breast cancer cells to doxorubicin-and etoposide-induced apoptosis. Cancer Res 2001;61(1):348-54.

26. O'Donovan N, Crown J, Stunell H, Hill AD, McDermott E, O'Higgins N, et al. Caspase 3 in breast cancer.Clin Cancer Res 2003;9(2):738-42.

27. Sharma S, Hiran KR, Pavithran K, Vijaykumar DK. A pilot study to assess the feasibility of evaluation of markers of response to chemotherapy at one day \& 21 days after first cycle of chemotherapy in carcinoma of breast: A prospective non-randomized observational study. World J Surg Oncol 2009 30;7:35 